\title{
PALAEOBIOGEOGRAPHY AND EVOLUTION OF LATE PALEOZOIC AMMONOIDS
}

\author{
HOUSE, Michael, Dept. of Geology, the University, Southampton SO9 5NH, England, U.K.
}

In recent years it has been recognised as a result of careful field work that there are a series of extinction events affecting goniatites and clymenids during the Devonian and early Carboniferous which can be confirmed in many parts of the world. Many have been given names, such as the Daleje, Chotec, Kacák, Pumilio, Taghanic, Kellwasser, Nehden, Condroz, Annulata, Hangenberg and Alum Shale Events. The Taghanic Event, which falls within the Givetian stage, is a major extinction event, as is the Upper Kellwasser Event at the end of the Frasnian and the Hangenberg Event near the end of the Devonian. At major events many familial and generic taxa are lost and few stocks, often of a particular type, survive; at smaller events, lower taxon levels are affected. The events are usually associated with sedimentary perturbations of some sort. These are usually linked with transgression, or regressive/transgressive couplets, and frequently with anoxia or hypoxic conditions; it has given emphasis to the concept of the ammonoid record as a bioseismograph of environmental events. Where documented in detail a gradual decline before the event is noticeable, and although this may appear stepped on diagrams, this results from the timeblocks used in analysis. Probably gradual extinction events occurred at Milankovitch band interval culminations. There is usually a trauma period of very low diversity, but not necessarily of abundance. Subsequent innovation and diversity is gradual. There is no evidence for sudden events such as might be caused by bolides or large meteorites, however much they might be expected.

A programme of research has studied these events in Europe, North America, North Africa and Western Australia, that is, on separate continents where sealevel changes can be documented by movements over stable shelf or cratonic areas. This has suggested that many are linked with eustatic events. The association with hypoxia is not universal although that is common in the eastern North America-Europe-North Africa area, then closely juxtaposed after the initiation of the docking of Gondwanaland against Laurussia. Comparisons of the Australian sealevel curves with those of North America and other areas suggest a correlation of pulses, especially for the Frasnian. But anoxic events have not been located at the Kellwasser and Hangenberg events in Western Australia, for example, to match those of other areas.

Since there are at least ten of these events, not all of the same power, in the interval from the late Lower Devonian to the basal Carboniferous, and since only two of them closely conform to stage boundaries (end Frasnian and end Famennian) it is misleading to plot these as stage or series blocks and to suggest there are extinctions at stage boundaries. Only in two cases (Upper Kellwasser and Hangenberg) would this be approximately true, but the staged decline at both would make even those misleading.

It is too early to speculate whether the events are periodic, or result from episodic culminations of different orbitally forced periodicities. However, many successions show smallscale rhythmic repetitions of facies which, when well developed, are the hallmark of some events. This might suggest a climatic control. The Taghanic Event, however, seems well correlated with the Taghanic Onlap (formerly known as the basal Upper Devonian transgression) suggesting a (plate) tectonic cause. It is important as a next stage to document the paleoecological changes of other groups over these events; already it is clear that other invertebrate groups are significantly affected by some. Precise documentation of tectonic events is also needed in the search for a cause. 